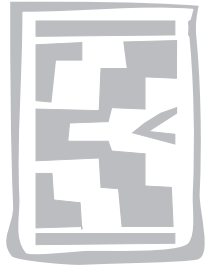

\title{
The pathology of tuberculosis caused by Mycobacterium tuberculosis in a herd of semi-free-ranging springbok (Antidorcas marsupialis)
}

\author{
T.A. GOUS* and M.C. WILLIAMS \\ Section of Pathology, Department of Paraclinical Sciences, Faculty of Veterinary Science \\ University of Pretoria, Private Bag X04, Onderstepoort, 0110 South Africa
}

\begin{abstract}
GOUS, T.A. \& WILLIAMS, M.C. 2009. The pathology of tuberculosis caused by Mycobacterium tuberculosis in a herd of semi-free-ranging springbok (Antidorcas marsupialis). Onderstepoort Journal of Veterinary Research, 76:419-441

The first detailed description of the pathology of tuberculosis, caused by Mycobacterium tuberculosis, in springbok is reported. The springbok were part of a semi-free-ranging herd kept on the grounds of iThemba Laboratory for Accelerator Based Science (LABS) in the Kuils River district of the Western Cape Province, South Africa. Mycobacterium tuberculosis was isolated from three animals out of a total of 33 sampled, with two animals showing tuberculosis lesions. The index case was an adult ewe that showed advanced miliary tuberculosis with marked macroscopic and microscopic lesions in the lungs, pleura and respiratory lymph nodes, and numerous acid-fast bacilli. Six healthy rams were sampled nine months later and a pilot study indicated miliary tuberculosis lesions in one ram, which again were macroscopically most prominent in the lungs, pleura and respiratory lymph nodes. Macroscopic lesions were also noted in the sternal, iliac, prefemoral and retropharyngeal lymph nodes. Microscopy in this animal revealed lesions in the macroscopically affected organs as well as numerous other lymph nodes, and suspected lesions occurred in the testicle and colon. Acid-fast bacilli were scarce to moderate in affected organs. Because of the miliary nature of the lesions in both affected animals, the route of infection could not be established conclusively. The lesions in most affected organs of both animals resembled classical tuberculous granulomas. A main study conducted on healthy animals 19 months after the pilot study failed to find any animal with tuberculosis lesions in the group of 25 sampled, and all were negative for mycobacteria via mycobacterial culture.
\end{abstract}

Keywords: Mycobacterium tuberculosis, pathology, semi-free-ranging, springbok

\section{INTRODUCTION}

Tuberculosis, caused by the bacterium Mycobacterium tuberculosis, also referred to as human tuberculosis (HTB), is an uncommon disease in species other than humans. It is a primary human pathogen but may infect domestic or wildlife species that are in close or prolonged contact with humans (Fourie 1983; Michalak, Austin, Diesel, Bacon, Zimmerman

\footnotetext{
* Author to whom correspondence is to be directed. Present address: Western Cape Provincial Veterinary Laboratory, Private Bag X5020, Stellenbosch, 7599 South Africa

Accepted for publication 16 April 2009-Editor
}

\& Maslow 1998; Michel \& Huchzermeyer 1998; Montali, Mikota \& Cheng 2001).

Although M. tuberculosis is the most common infection in humans, Mycobacterium bovis is responsible for an increasing proportion of human tuberculosis cases (O’Reilly \& Daborn 1995; Cosivi, Grange, Daborn, Raviglione, Fujikura, Cousins, Robinson, Huchzermeyer, De Kantor \& Meslin 1998). Much attention has been given to the zoonotic potential of tuberculosis in wildlife populations and the threat they present to human health (Fredrickson, Barton, Ragan \& Roberts 1971; Thoen 1988; Stetter, Mikota, Gutter, Monterosso, Dalovisio, Degraw \& Farley 
1995; Cosivi et al. 1998; Michalak et al. 1998; De Lisle, Mackintosh \& Bengis 2001). The reverse situation, however, has received little attention-the threat tuberculous humans present to wildlife.

Almost all reports published on HTB in indigenous wild animals in South Africa refer only to wild animals in captivity, notably non-human primates such as chacma baboons (Papio ursinus) and vervet monkeys (Cercopithecus aethiops) (Fourie 1983; Michel, Venter, Espie \& Coetzee 2003). Transmission to semi-free-ranging and free-ranging wildlife is an extremely rare occurrence and only one report describes HTB in free-ranging indigenous wildlife, viz. banded mongooses (Mungos mungo) in Botswana and suricates (Suricata suricatta) in South Africa (Alexander, Pleydell, Williams, Lane, Nyange \& Michel 2002).

In the rest of the world HTB in wild animals has been recorded exclusively in captive wildlife, and does not appear to occur naturally in free-living animals. The range of species infected includes nonhuman primates, elephants, ungulates, carnivores, marine mammals and psittacine birds (Thoen, Richards \& Jarnagin 1977; Forshaw \& Phelps 1991; Montali et al. 2001).

The first case of tuberculosis in a springbok (Antidorcas marsupialis) was recorded by Robinson in 1951 at the Pretoria Zoological Gardens (Robinson 1953). The animal was killed after a positive reaction to the tuberculin test, and post mortem examination revealed extensive tuberculous lesions in the lungs. Acid-fast bacilli were numerous in smears made from the lung lesions. Although pure cultures of $M$. tuberculosis were obtained, subsequent cultures from guinea pigs that were inoculated with affected lung material were considered to be of the bovine type. A pure culture of $M$. tuberculosis was obtained from an in-contact springbok that died shortly afterwards, but inoculation of guinea pigs was never attempted. The identity of the causative Mycobacterium species in both these cases is therefore, at best, equivocal. No description of the pathology was given in either of the animals other than "extensive tuberculosis lesions in the lungs". The paper by Hofmeyr (1956) mentions one case of tuberculosis in a springbok at the Pretoria Zoological Gardens, but gives no additional information regarding the causative Mycobacterium species or pathology.

In December, 1999 HTB was diagnosed in a springbok ewe that originated from a herd of semi-freeranging springbok that are kept on the grounds of the iThemba Laboratory for Accelerator Based Science (LABS) near Faure in the Kuils River district of the Western Cape Province, South Africa. Buildings on the 42 ha site are interspersed with artificially maintained kikuyu (Pennisetum clandestinum) and kweek (Cynodon dactylon) lawns, with groves of exotic alien vegetation consisting almost exclusively of Port Jackson willow (Acacia saligna). Apart from springbok, other semi-free-ranging game species on the premises include Burchell's zebras (Equus burchelli), bontebok (Damaliscus dorcas dorcas), grysbok (Raphicerus melanotis) and steenbok (Raphicerus campestris). When the initial case of tuberculosis was diagnosed in a springbok there were 48 springbok, six bontebok, four zebras and a few grysbok and steenbok present.

This study documents the pathology of HTB in the springbok of iThemba LABS. After the index case was diagnosed, an opportunity to examine more springbok presented itself on 26 September 2000 when the iThemba LABS Staff Environmental Club decided to cull six animals due to unsustainable numbers. One animal showed advanced generalized (miliary) tuberculosis, and M. tuberculosis was subsequently isolated from a pool of four organ specimens. This prompted the main study during which 25 animals were culled from April 2002 to July 2002 for detailed pathological and bacteriological investigation.

\section{MATERIALS AND METHODS}

\section{Part one: Index case}

\section{Animals}

On 20 December 1999 a prostrate and weakened adult springbok ewe was presented for necropsy at the Western Cape Provincial Veterinary Laboratory (WCPVL) in Stellenbosch to establish the cause of the clinical signs. The ewe was euthanased by means of an overdose of intravenous barbiturates and a full necropsy performed. Necropsy revealed the possibility of tuberculosis and various specimens to confirm the diagnosis were collected as indicated below.

On 29 June 2000 an old springbok ram was found dead at iThemba LABS after it had appeared "tired" for at least a week prior to death. The carcass was presented for necropsy at the WCPVL but advanced decomposition made detailed examination impossible. However, lesions suggestive of tuberculosis were present in the lungs, and specimens were collected as indicated below. 
Macro- and histopathology

All macroscopic lesions found at necropsy of the index case were recorded. The following tissue specimens were collected from the index case for histopathological examination and fixed in $10 \%$ buffered formalin: heart (multiple specimens), lung (multiple specimens), mediastinal lymph node, bronchial lymph node, liver, spleen, kidney, adrenal glands and alimentary tract (oesophagus, abomasum, small intestine, large intestine and rectum). Specimens from the ram consisted of lung tissue and pulmonary lymph nodes. The formalin-fixed tissues were embedded in paraffin wax and sections were cut at $5 \mu \mathrm{m}$ and routinely stained for histopathological study with haematoxylin and eosin (H\&E). All sections were also stained with Ziehl-Neelsen (ZN) stain to detect acid-fast bacilli. Microscopic lesions were recorded after light microscopic examination.

\section{Bacteriology}

A fresh unpreserved mediastinal lymph node that showed lesions suggestive of tuberculosis was aseptically collected from the index case. Two fresh unpreserved lung specimens were aseptically collected from the ram. These specimens were all frozen $\left(-20^{\circ} \mathrm{C}\right)$ and dispatched in a frozen state, within 5 days of collection, to the Tuberculosis Laboratory at the Onderstepoort Veterinary Institute (OVI) for mycobacterial culture.

The specimens were cultured for Mycobacterium spp. according to the standard isolation and identification methods for mycobacteria used by the OVI. These methods have been described (Anon. 1983; Bengis, Kriek, Keet, Raath, De Vos \& Huchzermeyer 1996; Keet, Kriek, Penrith, Michel \& Huchzermeyer 1996).

\section{Part two: Pilot study}

\section{Animals}

On 26 September 2000 the iThemba LABS Staff Environmental Club decided to cull six springbok due to unsustainable numbers. At this stage, HTB was known to be present within the herd and a pilot study was designed to evaluate these animals for the presence of tuberculosis. The animals were randomly selected by selecting every second animal encountered, and consisted of clinically healthy rams comprising three sub-adult and three adult animals. The animals were stunned before death by professional hunters using the intracranial gunshot method with .22 calibre rifles. As soon as each ani- mal fell to the ground the throat was cut to cause exsanguination and death. Animals were identified numerically and chronologically as they were euthanased, and then transported to the WCPVL for necropsy and sampling.

\section{Macro- and histopathology}

The main aim of the pilot study was to detect animals with macroscopic and microscopic tuberculosis lesions, and to describe the lesions in detail. The hallmark tuberculosis lesion is the granuloma, or tubercle (Dungworth 1993), and any macroscopic lesion resembling granulomatous inflammation was described. These were lesions showing any of the following characteristics: pinpoint to larger size, multiple to single, distinctly outlined or poorly demarcated, flat to elevated above the organ surface, pale to pigmented, with or without necrosis, calcification, liquefaction, abcessation or encapsulation.

Tissue specimens were collected for histopathological examination and all, except the lymph nodes and specimens for mycobacterial culture (see below), were fixed in $10 \%$ buffered formalin. These included the brain, eyes, heart (multiple specimens), lung (multiple specimens), liver, kidneys, spleen, adrenal glands, testes, thymus (if present) and alimentary tract (tongue, oesophagus, abomasum, duodenum, jejunum, ileum and colon). Specimens from other organs and tissues were only collected if macroscopic abnormalities were noted.

Fresh unpreserved lymph nodes were collected aseptically and each lymph node placed in a separate sterile container for processing within $24 \mathrm{~h}$ of collection which entailed aseptic sectioning of each lymph node into thin (1-2 mm) slices for macroscopic evaluation. Specimens from each lymph node were then placed in $10 \%$ buffered formalin, and the remainder dispatched for mycobacterial culture. Lymph nodes sampled included the tonsils, parotid (left and right), retropharyngeal (left and right), mandibular (left and right), bronchial, mediastinal, sternal, hepatic, splenic, ileocaecal, mesenteric, iliac, inguinal, prescapular (left and right), prefemoral (left and right) and popliteal (left and right) lymph nodes.

The formalin-fixed tissues were embedded in paraffin wax and sections were cut at $5 \mu \mathrm{m}$ and stained with H\&E and ZN. Microscopic lesions were recorded after light microscopic examination.

The suspect macroscopic granulomatous lesions were confirmed and described microscopically. Additional granulomatous inflammatory lesions not 
detected macroscopically, were given microscopic descriptions. For the purpose of this study, microscopic granulomatous inflammation was defined as a lesion showing any combination of the following: central caseous or coagulative necrosis, with or without calcification, surrounded by macrophages, epithelioid cells and multinucleated giant cells, and more peripherally lymphocytes, plasma cells, macrophages and varying degrees of fibroplasia, with or without encapsulation. The reaction may be modified by haemorrhage, accumulation of fibrin and neutrophil infiltration. The presence or absence, location and relative numbers of acid-fast bacilli were noted after ZN staining.

\section{Bacteriology}

Specimens for mycobacterial culture comprised fresh unpreserved tissue samples from the lung (multiple specimens), liver, spleen, kidneys, ileum and all the lymph nodes listed above. These specimens were placed in individual sterile containers and immediately refrigerated at $2-4{ }^{\circ} \mathrm{C}$. The lymph nodes were processed as indicated above. Specimens were then frozen $\left(-20^{\circ} \mathrm{C}\right)$ and dispatched in a frozen state, within five days of collection, to the Tuberculosis Laboratory at the OVI for mycobacterial culture, where they were pooled into the following four groups per animal: lungs, other organs (liver, spleen, kidneys and ileum), organ lymph nodes (bronchial, mediastinal, hepatic, splenic, ileocaecal and mesenteric) and carcass lymph nodes [tonsils, parotid (left and right), retropharyngeal (left and right), mandibular (left and right), sternal, iliac, inguinal, prescapular (left and right), prefemoral (left and right) and popliteal (left and right)]. These tissue pools were each cultured for Mycobacterium spp. according to the same protocol mentioned above.

\section{Part three: Main study}

\section{Animals}

In 2002 the springbok numbers had increased to 62 animals and the iThemba LABS Staff Environmental Club decided to cull several of them, which afforded the opportunity to sample more animals for tuberculosis investigations. Professional hunters were employed to cull 25 animals, consisting of 15 adult ewes and ten adult rams, from April 2002 to July 2002. One ewe showed right hind leg lameness, while the others all appeared clinically healthy and were randomly selected. Random selection was achieved by shooting every second animal encountered. The animals were shot in batches of between five and ten animals per day of sampling. Euthanasia was performed as described above. Animals were identified numerically and chronologically as they were euthanased, and transported to the WCPVL for necropsy and sampling.

\section{Macro- and histopathology}

Similar to that of the pilot study, the aim of the main study was to detect animals with macroscopic and microscopic tuberculosis lesions, and to describe the lesions in detail. The same macroscopic and microscopic criteria for evaluation were therefore applied.

Tissue specimens were collected for histopathological examination and all, except the lymph nodes and specimens for mycobacterial culture, were fixed in $10 \%$ buffered formalin. These included specimens from the brain, eyes, heart (multiple specimens), lung (multiple specimens), liver, kidneys, spleen, adrenal glands, testes, ovaries, uterus, mammary gland, urinary bladder, pancreas and alimentary tract (tongue, oesophagus, rumen, abomasum, duodenum, jejunum, ileum and colon). Specimens from other organs were only collected if macroscopic abnormalities were noted.

Fresh unpreserved lymph nodes were collected, handled and processed as described above. Lymph nodes sampled included the tonsils, parotid (left and right), retropharyngeal (left and right), mandibular (left and right), bronchial, mediastinal, ileocaecal, mesenteric, iliac, inguinal, prescapular (left and right), prefemoral (left and right) and popliteal (left and right) lymph nodes.

The formalin-fixed tissues were processed, stained and examined for granulomatous inflammation in a similar fashion to those of the pilot study.

\section{Bacteriology}

Specimens for mycobacterial culture comprised fresh unpreserved lung (multiple specimens), all the lymph nodes listed above and any other organ that showed suspected tuberculosis lesions. These specimens were placed in individual sterile containers, immediately refrigerated at $2-4^{\circ} \mathrm{C}$ and the lymph nodes processed as for the pilot study. After macroscopic examination of the lymph nodes, they were pooled into four groups as follows: head (tonsils, parotid, retropharyngeal and mandibular), thoracic (bronchial and mediastinal), abdominal (mesenteric and ileocaecal), peripheral (prescapular, prefemoral, popliteal and inguinal). Specimens were then frozen $\left(-20^{\circ} \mathrm{C}\right)$ and dispatched in a frozen state, 
within five days of collection, to the Tuberculosis Laboratory at the OVI for mycobacterial culture.

At the OVI the lymph node pools, lungs, and other organ specimens were each cultured individually for Mycobacterium spp. according to the protocol outlined above.

\section{RESULTS}

\section{Part one: Index case}

The index case was an adult ewe (A1) and a second possible case an adult ram (A2)

\section{Macroscopic pathology}

A1 showed marked emaciation. Hard and dry faecal pellets were present in the rectum, resulting in constipation and rectal prolapse. There was depletion of peri-renal and mesenteric fat reserves, and the fat in the coronary groove of the heart and bone marrow cavity was soft, translucent and jelly-like (serous atrophy of fat). These changes reflected marked cachexia. The carcass of A2 showed advanced post mortem autolysis and putrefaction with evidence of post mortem predation. Significant lesions were found in the following organs:

\section{LUNG}

The lungs of $A 1$ showed moderate numbers of multifocal, firm, round to oval, greyish white, nodular granulomatous lesions throughout the lungs that were more numerous in the caudal lobes. The nodules measured $1-10 \mathrm{~mm}$ in diameter. Some of the granulomatous nodules displayed irregular, multifocal, central, yellowish, caseous necrotic foci measuring $2-5 \mathrm{~mm}$ in diameter, with moderate calcification, and were moderately encapsulated.

The entire visceral and parietal pleura of A1 was covered in moderate numbers of multifocal, round to ovoid, non-encapsulated, translucent to greyish white plaques and nodules measuring $1-10 \mathrm{~mm}$ in diameter. These nodules resembled "TB-grapes" and consisted mostly of fibrous connective tissue showing no to few, multifocal, irregularly shaped, pale yellowish, central caseous necrosis measuring 1-5 $\mathrm{mm}$ in diameter, and often prominent calcification.

The right lung lobe of A2 was consolidated, and both lobes showed a few round to oval, whitish, firm, nodular areas, measuring $1-10 \mathrm{~mm}$ in diameter, which were considered to be granulomas.
These lesions, which were suspected to be tuberculosis were more numerous in the cranial lobes.

There were moderate (A2) to large (A1) numbers of adult Bronchonema magna nematodes present in the lumen of the trachea at the tracheal bifurcation.

\section{LYMPH NODE}

The bronchial and mediastinal lymph nodes of $A 1$ were enlarged and measured $30 \times 10 \mathrm{~mm}$, and $50 \mathrm{x}$ $10 \mathrm{~mm}$, respectively. Both lymph nodes showed multifocal to confluent irregular areas, measuring 1-10 $\mathrm{mm}$ in diameter, of pale yellowish caseous necrosis with prominent calcification. The necrotic areas were moderately encapsulated.

\section{SPLEEN}

The spleen of A1 was moderately enlarged and had an increased ("meaty") consistency. The red pulp was prominent and the white pulp indistinct.

\section{LIVER}

The liver of A1 showed moderate hepatomegaly with focally disseminated necrosis, the latter being represented by numerous pinpoint, pale white foci distributed throughout the parenchyma.

\section{KIDNEY}

The kidneys of $A 1$ were pale brown and moderately swollen.

\section{ADRENAL GLAND}

Both adrenal glands of $A 1$ displayed marked enlargement of the cortex as a result of hyperplasia.

\section{Histopathology}

The microscopic appearance of the lesions in the organs mentioned above, as well as significant lesions detected in other organs, are described below. The multinucleated giant cells encountered were always a mixed cell population consisting of both the Langhans' and foreign-body types, except when otherwise stated. No acid-fast bacilli were encountered in the organs that did not show significant lesions.

\section{LUNG}

There were numerous multifocal to confluent necrogranulomas visible throughout the lung parenchyma of $A 1$. These consisted of a central area of caseous necrosis that was usually calcified, surrounded by a 
rim of moderate numbers of macrophages and epithelioid cells, and low numbers of multinucleated giant cells. There was an outer layer of lymphocytes and plasma cells, within a moderately developed fibrous capsule. Numerous multifocal smaller, and often indistinctly outlined granulomas, without necrosis and calcification, consisting of macrophages, epithelioid cells, lymphocytes and plasma cells were also visible. These smaller granulomas were often infiltrated by low to moderate numbers of neutrophils. The remainder of the lungs showed multifocal areas of alveolar neutrophil infiltration admixed with moderate to large numbers of macrophages. Low to moderate numbers of macrophages were also present in alveolar walls.

A few bronchioles in the lung of A1 contained sections of numerous nematode parasites. Lesions that were ascribed to this nematode infection consisted of moderate to marked hyperplasia and hypertrophy of bronchiolar epithelium and smooth muscle. The lamina propria of the bronchiolar epithelium was infiltrated by moderate numbers of lymphocytes and plasma cells, and small numbers of eosinophils. Moderate numbers to numerous globular leukocytes, with moderate to abundant, variably-sized, round, eosinophilic, cytoplasmic globules, occurred in the intercellular areas of the bronchiolar epithelium. The bronchiolar- and perivascular-associated lymphoid tissue was moderately hyperplastic. Some bronchioles, notably those parasitized by adult nematodes, were filled with a moderate amount of exudate consisting of fibrin, neutrophils, eosinophils and small numbers of macrophages.

Ziehl-Neelsen staining of the lungs of $A 1$ revealed numerous medium-sized, slender, acid-fast bacilli in the cytoplasm of macrophages, epithelioid cells and multinucleated giant cells in necrogranulomas along the edge of the necrotic centre. Bacilli were also present in moderate numbers in macrophages and epithelioid cells of the smaller granulomas. Freelying acid-fast bacilli in brionchioles were admixed with cellular debris, and there were also bacilli in the cytoplasm of intra-brionchiolar macrophages.

The lungs of A2 were markedly autolysed and putrefied, with the presence of numerous bacteria many of which morphologically resembled Clostridium spp. There were multifocal areas of what appeared to be coagulative and caseous necrosis, separated from the adjacent lung tissue by a prominent reaction zone consisting of haemorrhage, fibrin exudation and possible neutrophils. Large numbers of Gram-negative cocco-bacilli were present in the necrotic areas and reaction zone. The remainder of the lungs of this animal showed marked haemorrhage, protein-rich alveolar oedema, fibrin exudation and widespread alveolar macrophage infiltration. All sections stained negatively for the presence of acid-fast bacilli with ZN staining. The lung lesions in A2 probably reflected necrotic bacterial pneumonia with possible early abscessation.

\section{LYMPH NODE}

The mediastinal lymph nodes of A1 displayed large multifocal to confluent necrogranulomas, involving almost the entire lymph node, with only a small rim of relatively normal tissue remaining. These necrogranulomas consisted of a central caseous necrotic area that was usually moderately calcified, with a surrounding layer of low to moderate numbers of macrophages, epithelioid cells and multinucleated giant cells. A few extremely large giant cells, containing numerous centrally located nuclei, were visible. The outer layer consisted of a well-developed fibrous capsule that was infiltrated by moderate numbers of lymphocytes and plasma cells, and low to moderate numbers of haemosiderin-containing macrophages. A few smaller granulomas, consisting of macrophages and epithelioid cells, with peripheral lymphocyte and plasma cell infiltration, were also visible. The relatively normal lymph node tissue showed numerous multifocal nests, consisting of macrophages, epithelioid cells and multinucleated giant cells.

The bronchial lymph nodes of A1 showed less extensive but otherwise similar lesions to the above. Additionally, there were mutifocal areas of coagulative necrosis in the relatively normal lymph node tissue that were infiltrated by moderate to large numbers of neutrophils. The medullas were infiltrated by large numbers of macrophages, many of which showed erythrophagocytosis.

In the mediastinal and bronchial lymph nodes of $A 1$ large numbers of medium-sized, slender, acid-fast bacilli were present along the edges of the necrotic caseous exudate. The bacilli often formed thick clumps. Acid-fast bacilli were also present in large numbers in the cytoplasm of macrophages, epithelioid cells and multinucleated giant cells surrounding the necrotic centre, as well as in the multifocal nests formed by these cells.

The respiratory lymph nodes of A2 showed similar advanced post mortem changes to the lungs. There was a focal area of suspected coagulative necrosis in the cortex, with accumulation of fibrin and necrotic cellular debris. Ziehl-Neelsen staining was negative for acid-fast bacilli in this animal. 
SPLEEN

The spleen of A1 showed marked multifocal to confluent necrotic to necrogranulomatous splenitis. This was represented by numerous foci of coagulative to caseous necrosis of macrophage aggregates in the red pulp. The necrotic areas were infiltrated by moderate numbers of neutrophils. Moderate numbers of macrophages, and low numbers of multinucleated giant cells, were also present throughout the red pulp. There was moderate extramedullary haematopoiesis. Medium-sized, slender, acid-fast bacilli were numerous in the cytoplasm of most macrophages.

\section{LIVER}

The liver of A1 displayed marked focally disseminated coagulative necrosis of hepatocytes, with mild to moderate neutrophil and macrophage infiltration. The sinusoids and portal tracts were infiltrated by low to moderate numbers of macrophages, and low numbers of multinucleated giant cells, that often formed small microgranulomas. Moderate numbers of macrophages occurred in the portal venules and lymphatics, as well as in the central veins. There was a focal area of capsular fibroplasia and mature fibrosis. In sections stained with ZN there were numerous medium-sized, slender, acid-fast bacilli in necrotic areas, and low to moderate numbers in the cytoplasm of macrophages of both the macrophages occurring throughout the liver, as well as those inside portal venules and lymphatics, and central veins.

\section{KIDNEY}

Numerous multifocal necrogranulomas occurred in the cortex and cortico-medullary junction in the kidney of $A 1$. These microgranulomas consisted of low to moderate numbers of macrophages in their centres, some of the cells being necrotic and surrounded by moderate to large numbers of lymphocytes and plasma cells. In ZN-stained sections large numbers of medium-sized, slender, acid-fast bacilli were found in the cytoplasm of macrophages in the microgranulomas, but were also noted in scattered individual macrophages. A few such bacilli were also present in the cytoplasm of mesangial cells in a few renal corpuscles.

\section{ADRENAL GLAND}

The adrenal gland of $A 1$ showed marked hyperplasia of the zona fasciculata with marked accumulation of clear, single to multiple, variably-sized, round vacuoles in the cytoplasm of the cells, representing lipid droplets. Scattered cells in this zone were necrotic. There was scanty macrophage infiltration in the sinusoids of all zones of the cortex. ZN staining revealed moderate numbers of medium-sized, slender, acid-fast bacilli, often forming clumps, in the cytoplasm of macrophages and scattered parenchymal cells of all zones of the cortex.

\section{GASTRO-INTESTINAL TRACT}

The small intestine, colon and rectum of $A 1$ showed scanty to low numbers of multifocal nests of macrophages in the lamina propria of the mucosa. These organs, as well as the abomasum, also had small numbers of widely scattered individual macrophages in the same location. The lamina propria of the mucosa of the small intestine was also infiltrated by moderate numbers of lymphocytes and plasma cells. Scanty nematode larvae were present in gastric glands of the mucosa of the abomasum, without an inflammatory reaction. Ziehl-Neelsen staining of the abomasum, small intestine, colon and rectum revealed low to moderate numbers of mediumsized, slender, acid-fast bacilli in the cytoplasm of macrophages located in the mucosa.

\section{Bacteriology}

Mycobacterium tuberculosis was isolated from a mediastinal lymph node of $A 1$. The lung specimens from A2 were negative for Mycobacterium spp. after 10 weeks' incubation.

\section{Part two: Pilot study}

Three adult (B3, B5 and B6) and three sub-adult (B1, B2 and B4) rams were sampled.

\section{Macroscopic pathology}

All the animals were in good condition, except for B4 which showed moderate emaciation. B2 and B6 did not show any noteworthy macroscopic lesions. Significant lesions were found in the following organs of the other animals:

\section{LUNG}

The lungs of B4 showed lesions highly suggestive of tuberculosis. There were four large and fairly distinctly demarcated, multifocal, granulomatous, nodular lesions. One which was situated in the cranial edge of the left cranial lobe, was irregularly ovoid and $20 \times 10 \mathrm{~mm}$ in size, yellowish, granulomatous and non-encapsulated. Two granulomas that occurred in the dorso-caudal area of the left and right 
caudal lobe respectively, were similar in appearance. They were round and $20 \mathrm{~mm}$ in diameter, and had an indistinct arborescent central area of yellowish caseous necrosis containing numerous individual necrotic foci measuring 1-2 $\mathrm{mm}$ in diameter. The individual necrotic foci and entire nodules were surrounded by mildly developed fibrous connective tissue. The fourth granuloma occurred in the craniomedial aspect of the right caudal lobe and was round, $30 \mathrm{~mm}$ in diameter with a central, pale yellow, caseous necrotic area surrounded by a welldeveloped fibrous capsule. Apart from these large nodular granulomas, there were numerous non-encapsulated, multifocal to confluent, translucent to greyish white, round to irregular granulomas measuring $1-5 \mathrm{~mm}$ in diameter distributed throughout the lung parenchyma.

The entire visceral and parietal pleura was covered in numerous, multifocal to confluent, round to ovoid, translucent to pale whitish, non-encapsulated plaques and nodules, measuring $1-10 \mathrm{~mm}$ in diameter. These nodules resembled "TB-grapes" and consisted mostly of fibrous connective tissue showing no or mild multifocal areas of pale yellowish caseous necrosis measuring $1-5 \mathrm{~mm}$ in diameter on cut section.

B5 displayed moderate numbers of adult $B$. magna nematodes in the lumen of the trachea and both bronchi, especially at the tracheal bifurcation.

\section{LIVER}

The livers of B1, B3 and B4 showed scanty to low numbers of multifocal, round, distinctly outlined, pinpoint to $3 \mathrm{~mm}$ diameter, pale white foci randomly distributed throughout the parenchyma.

\section{LYMPH NODES}

The following lymph nodes of B4 showed macroscopic lesions highly suggestive of tuberculosis:

- Bronchial: Multifocal to coalescing, non-encapsulated, round to ovoid, pale yellowish, caseous necrotic to granulomatous areas measuring 1$15 \mathrm{~mm}$ in diameter, with mild to moderate calcification.

- Mediastinal: Multifocal to coalescing, non-encapsulated, ovoid to irregular, granulomatous areas measuring 2-18 $\mathrm{mm}$ in diameter. There was a small focal, round, $1 \mathrm{~mm}$-diameter area of dull yellowish necrosis.

- Sternal: Multifocal, non-encapsulated, round, white to slightly yellow, necrotic areas of up to $1 \mathrm{~mm}$ in diameter, and a focal, round, non-encapsulated area of granulomatous inflammation measuring $4 \mathrm{~mm}$ in diameter.

- Iliac: Multifocal, encapsulated, round to oval, pale yellowish, caseous necrotic foci measuring 3$7 \mathrm{~mm}$ in diameter, with moderate calcification.

- Right prefemoral: Focal, non-encapsulated, round area of yellowish caseous necrosis measuring $3 \mathrm{~mm}$ in diameter, with moderate calcification.

- Right retropharyngeal: Focal, non-encapsulated, round area of slightly yellow-tinged necrosis measuring $1 \mathrm{~mm}$ in diameter.

\section{Histopathology}

The microscopical lesions in the organs mentioned above, as well as significant lesions detected in other organs, are described below. The multinucleated giant cells encountered were always a mixed cell population consisting of both the Langhans' and foreign-body types, except when otherwise stated. All lesions in all organs were negative for acid-fast bacilli, except where otherwise stated.

\section{LUNG}

The lungs of B4 showed numerous multifocal to confluent necrogranulomas throughout the parenchyma. The necrogranulomas consisted of a central area of caseous necrosis that was often moderately calcified, surrounded by large numbers of macrophages and epithelioid cells, and low to moderate numbers of multinucleated giant cells. Enveloping this layer was an outer layer consisting of low to moderate numbers of lymphocytes and plasma cells, within a moderately developed fibrous capsule. Some granulomas did not show central necrosis. In a few necrogranulomas there was infiltration of moderate numbers of neutrophils into the necrotic centre with occasional pus formation. The surrounding bronchioles were plugged with necrotic cellular debris consisting of neutrophils, macrophages and respiratory epithelial cells.

The pleura showed a proliferative response characterized by prominent fibroplasia with moderate numbers of multifocal to confluent granulomas in some of which were areas of coagulative to caseous necrosis in their centres. The granulomas consisted of large numbers of macrophages and epithelioid cells, and moderate numbers of lymphocytes and plasma cells. Scanty to low numbers of neutrophils infiltrated the granulomas. The mesothelium showed moderate hypertrophy and hyperplasia. 
Ziehl-Neelsen staining of the lungs and pleura revealed small numbers of medium-sized, slender acid-fast bacilli in the cytoplasm of macrophages, epithelioid cells and multinucleated giant cells of the granulomas. Moderate numbers of acid-fast bacilli were present along the peripheral edge of the necrotic exudate in some necrogranulomas.

The lungs of B5 displayed small numbers of sections of adult nematodes in some bronchioles. There was mild to moderate epithelial and smooth muscle hypertrophy and hyperplasia of bronchioles, with infiltration of small numbers of eosinophils, lymphocytes and plasma cells in the lamina propria of the bronchiolar epithelium, and occasionally perivascularly. Small numbers of globular leukocytes, with moderate to abundant, variably-sized, round, eosinophilic, cytoplasmic globules, occurred in the intercellular areas of the bronchiolar epithelium.

\section{LIVER}

The multifocal pale white foci in the livers of B1, B3 and B4 seen macroscopically consisted of nodular portal aggregations of moderate to large numbers of lymphocytes and plasma cells; scanty eosinophils and macrophages were found in them only in B4. The liver of B5 showed a focal lesion similar to those of B4 but with only scanty eosinophil infiltration but no macrophages. A small focal granuloma occurred in the parenchyma of $\mathrm{B} 5$, which consisted of central caseous necrosis surrounded by small numbers of macrophages, epithelioid cells and eosinophils. All animals showed infiltration of scanty to low numbers of lymphocytes, plasma cells and eosinophils in the portal tracts, without the formation of distinct nodules. The liver lesions were possibly a response to a previous parasitic larval migration.

\section{LYMPH NODES}

The lymph nodes of B4 that had macroscopic lesions showed the following changes:

- Bronchial: There were multifocal to confluent necrogranulomas consisting of a central caseous necrotic area that was moderately calcified, with a surrounding layer of moderate numbers of macrophages, epithelioid cells and scanty multinucleated giant cells, admixed with moderate numbers of lymphocytes and plasma cells. There was a poorly to moderately developed outer fibrous capsule. Numerous small multifocal granulomas, that did not show central necrosis and calcification, occurred in the remainder of the lymph node. These granulomas consisted of small numbers of macro- phages, epithelioid cells and numerous (mostly Langhans') giant cells. Ziehl-Neelsen staining revealed small numbers of medium-sized, slender, acid-fast bacilli in the peripheral edge of the necrotic centre of necrogranulomas, and also in the cytoplasm of macrophages surrounding the necrotic centre.

- Mediastinal: Multifocal to coalescing granulomatous lymphadenitis, represented by numerous small granulomas composed of small numbers of macrophages and epithelioid cells, and numerous, mostly Langhans', giant cells. One granuloma showed mild central calcification. Very rare medium-sized, slender, acid-fast bacilli were present in the cytoplasm of epithelioid cells and multinucleated giant cells following ZN staining.

- Sternal: There was a focal granuloma that displayed central caseous necrosis with moderate calcification. This was surrounded by moderate numbers of macrophages and epithelioid cells, and scanty multinucleated giant cells, admixed with moderate numbers of lymphocytes and plasma cells. There was a poorly-developed fibrous capsule. Numerous small multifocal granulomas, similar in appearance to the small granulomas in the bronchial lymph node, occurred in the remainder of the lymph node. Ziehl-Neelsen staining revealed rare medium-sized, slender, acid-fast bacilli in the peripheral edge of the necrotic centre of the necrogranuloma, and also in the cytoplasm of macrophages that occurred in the small granulomas.

- lliac: There were multifocal necrogranulomas, similar in appearance to the necrogranulomas in the bronchial lymph node, but with more numerous multinucleated giant cells and a well-developed fibrous capsule. A few small granulomas, consisting of low numbers of macrophages and epithelioid cells, occurred in the remainder of the lymph node. The pattern of ZN staining was similar to that in the bronchial lymph node.

- Right prefemoral: There were multifocal necrogranulomas, similar in appearance to the necrogranulomas in the bronchial lymph node, but with large numbers of multinucleated giant cells. The necrogranulomas were surrounded by a few satellite granulomas, some showing central caseous necrosis, composed of moderate numbers of macrophages, epithelioid cells, multinucleated giant cells, lymphocytes and plasma cells. Most showed a moderately developed outer fibrous capsule. The pattern of $\mathrm{ZN}$ staining was similar to that in the bronchial lymph node. 
- Right retropharyngeal: There was a focal granuloma that consisted of central caseous necrosis with early calcification, surrounded by numerous macrophages and epithelioid cells, admixed with small numbers of lymphocytes, plasma cells and neutrophils. The macrophages and epithelioid cells exhibited occasional round, variably-sized, single to multiple, clear cytoplasmic vacuoles resembling fat gobules. The granuloma had an outer layer of poorly developed fibrous connective tissue. The remainder of the lymph node showed numerous scattered macrophages, epithelioid cells and multinucleated giant cells that were occasionally arranged in granulomas. Ziehl-Neelsen staining revealed very rare medium-sized, slender, acid-fast bacilli in the peripheral edge of the necrotic centre of necrogranulomas, and also in the cytoplasm of macrophages surrounding the necrotic centre.

The microscopic lesions in lymph nodes of B4 that did not exhibit macroscopic abnormalities were as follows:

- Left retropharyngeal: There was one poorly-developed granuloma in the cortex that consisted of small numbers of macrophages and epithelioid cells, and scanty multinucleated giant cells. Scanty individual Langhans' giant cells occurred in the cortex and paracortex.

- Left mandibular, right mandibular and left prescapular: There was moderate sinus histiocytosis with a few nests composed of small to moderate numbers of macrophages in the cortex.

- Left prefemoral: A focal granuloma occurred in the cortex and consisted of a central necrotic area that was completely calcified, surrounded by moderate numbers of macrophages and epithelioid cells, numerous multinucleated giant cells and small numbers of lymphocytes, plasma cells, neutrophils and eosinophils. There was a poorly-developed fibrous capsule. Very scanty mediumsized, slender, acid-fast bacilli were present in the cytoplasm of macrophages after ZN staining.

- Mesenteric: There were moderate numbers of small granulomas consisting of moderate numbers of Langhans' giant cells, and smaller numbers of macrophages and epithelioid cells. Scanty individual multinucleated giant cells were also visible.

- lleocaecal: A few small granulomas consisting almost exclusively of multinucleated giant cells occurred in the cortex. One multinucleated giant cell displayed characteristics of both Langhans' and foreign-body giant cells, i.e. with nuclei arranged both in a row along the periphery of the cell, and as a group centrally.

- Inguinal: There was a single small granuloma in the cortex which consisted of a few macrophages. Two large individual multinucleated giant cells (one each of the Langhans and foreign-body type) occurred in the cortex.

There was a nest of short, acid-fast bacilli in the cytoplasm of a macrophage in the medulla of a mesenteric lymph node of B2, unaccompanied by an inflammatory reaction. The lymph node also showed small multifocal areas of calcification in the cortex and medulla, and marked sinus histiocytosis.

Lesions in the mesenteric lymph nodes of $B 1$ and $B 5$, and the ileocaecal lymph node of B1 reflected nematode larval migration. B1 showed two granulomas in the ileocaecal lymph node, one each in the cortex and capsule, and one cortical granuloma in the mesenteric lymph node. The cortical ileocacecal granuloma displayed remnants of a nematode larva that was surrounded by numerous multinucleated giant cells, and small numbers of macrophages and epithelioid cells. The capsular granuloma displayed a similar reaction, but without nematode larval remnants visible. The granuloma in the mesenteric lymph node of B1 showed mild central coagulative necrosis, surrounded by small numbers of macrophages and epithelioid cells. B5 showed a focal granuloma in the cortex of a mesenteric lymph node that resembled the cortical ileocaecal granuloma of B1.

\section{DIAPHRAGM}

The parietal pleura covering the diaphragm of B4 displayed lesions similar to those in the lung pleura, but with the presence of mild central calcification of necrogranulomas. Ziehl-Neelsen staining was positive for scanty medium-sized, slender, acid-fast bacilli in the cytoplasm of a few epithelioid cells in necrogranulomas.

\section{TESTES}

The testes of B4 showed infiltration of moderate numbers of lymphocytes and plasma cells, and scanty to small numbers of macrophages in the interstitium. There were scanty microgranulomas, consisting of macrophage nests surrounded by small numbers of lymphocytes and plasma cells.

\section{GASTRO-INTESTINAL TRACT}

The colon of B4 displayed four granulomas, one in the submucosa, two in the muscle layer and one in 
the serosa. The submucosal granuloma showed a central nematode larva within necrotic tissue that was infiltrated by scanty eosinophils, and surrounded by numerous multinucleated giant cells and smaller numbers of macrophages, epithelioid cells, lymphocytes and plasma cells. The other three granulomas were similar in appearance, but without the central nematode larva, necrosis and eosinophils, and only scanty multinucleated giant cells. There was a focal granuloma in the submucosa of B5 that consisted of a few central multinucleated giant cells surrounded by moderate numbers of macrophages, epithelioid cells, lymphocytes, plasma cells and eosinophils.

The colon of all six animals showed scanty to small numbers of coccidia, in various stages of their lifecycle, in the epithelium of the mucosa of the colon, without an inflammatory reaction. There was a single nematode larva visible in a mucosal gastric gland of the abomasum in B4, without a noticeable inflammatory reaction.

\section{Bacteriology}

Mycobacterium tuberculosis was isolated from all organ pools of $\mathrm{B} 4$, and the organ lymph node pool of B6. Mycobacteria other than tuberculosis (MOTT) were isolated from the lungs, organ lymph nodes and carcass lymph nodes of B2, and organ lymph nodes and organs other than the lungs of B3.

\section{Part three: Main study}

Fifteen adult ewes (C1, C2, C3, C4, C5, C6, C7, C8, C10, C11, C12, C13, C14, C19 and C22) and 10 adult rams (C9, C15, C16, C17, C18, C20, C21, C23, C24 and C25) were sampled.

\section{Macroscopic pathology}

All the animals were in good condition and only $\mathrm{C} 1$ showed clinical signs consisting of right hind leg lameness before euthanasia. Ewes C3, C11, C12, $\mathrm{C} 13$ and C22 were in the early stages of pregnancy, while ewes $\mathrm{C} 2$ and $\mathrm{C} 6$ were in an advanced stage of pregnancy. C4, C7 and C8 did not show any noteworthy macroscopic lesions. Significant lesions were found in the following organs of the other animals:

\section{KIDNEY}

In the right kidney of $\mathrm{C} 1$ was a lesion highly suggestive for tuberculosis. In the cortex there was a focal, round, fairly distinctly demarcated, $8 \mathrm{~mm}$ diameter, dull-white, nodular, granulomatous lesion that bulged slightly from the surface. The nodule showed central caseation and was encapsulated by a fairly well-developed fibrous capsule. Part of this nodule was pooled with specimens from the uterus of $\mathrm{C} 1$ (see below) and submitted for mycobacterial culture.

\section{LIVER}

There were scanty to small numbers of round, distinctly outlined, pinpoint to $3 \mathrm{~mm}$ diameter, pale white foci randomly distributed throughout the parenchyma in the livers of C3, C9, C10, C11, C12, C13, C14, C15, C16, C17, C18, C19, C20, C21, C22, C23, C24 and C25.

\section{LYMPH NODE}

Both prescapular lymph nodes and the right mandibular lymph node of $\mathrm{C} 1$ were enlarged and showed significant proliferative changes consisting of multifocal to confluent, indistinctly outlined, oval to round nodules measuring $4 \mathrm{~mm}$ (right prescapular lymph node) and $15 \mathrm{~mm}$ (left prescapular and right mandibular lymph nodes) in diameter throughout the node. These nodules were moderately firmer in consistency than the rest of the lymph node.

The right parotid and right retropharyngeal lymph nodes of C9 were enlarged and both showed marked focal, proliferative, indistinctly outlined, oval nodules measuring $23 \times 10 \mathrm{~mm}$ (right parotid lymph node) and $15 \times 10 \mathrm{~mm}$ (right retropharyngeal lymph node) in the cortex. These nodules were firmer in consistency than the rest of the lymph node. The right parotid lymph node showed poor distinction between the medulla and cortex.

All of the above lymph node changes probably reflected marked reactive follicular hyperplasia, but early tuberculous granulomatous inflammation could not be ruled out macroscopically.

\section{SKELETAL MUSCLE}

The gastrocnemius muscles of $\mathrm{C} 20$ showed bilaterally symmetrical, focal, $5 \times 20 \mathrm{~mm}$ accumulations of a gritty, granular, pale white material, resembling calcified tissue, underneath the outer muscle sheath.

\section{UTERUS}

The endometrium of $\mathrm{C} 1$ showed multifocal petechiae. There were well-developed caruncules that showed multifocal petechiae and ecchymoses, and multifocal dull yellow-white areas of necrosis meas- 
uring from pinpoint to $3 \mathrm{~mm}$ in diameter. The caruncules were covered with a moderate amount of purulent exudate. There were multifocal petechiae and ecchymoses measuring $3-5 \mathrm{~mm}$ in diameter in the cervical mucosa. Several specimens of affected tissue from the uterus and cervix were pooled with a specimen from the kidney (see above) of $\mathrm{C} 1$ and submitted for mycobacterial culture. The uterus of C5 was congested and displayed similar haemorrhagic lesions to those seen in $\mathrm{C} 1$. However, no areas of necrosis or purulent inflammation were visible.

\section{LUNG}

The following animals had moderate numbers of adult $B$. magna nematodes present in the lumen of the trachea and both bronchi, notably at the tracheal bifurcation: C2, C5, C10, C24 and C25.

\section{ABDOMINAL CAVITY}

Several mature unidentified cestode larvae that morphologically resembled Taenia hydatigena cysticerci were visible in the abdominal cavity of $\mathrm{C} 3$ and $\mathrm{C} 1$. They were attached to the liver (C3) and abomasum (C1), or were lying loose and unattached (C1). Three cestode larvae of C1 that were attached to the abomasum, and one that was lying loose, were firm, round to irregularly-shaped nodules consisting of a calcified and inspissated centre, surrounded by a fairly well-developed fibrous capsule. The three nodules attached to the abomasum measured $15 \mathrm{~mm}$ in diameter while the loose nodule measured $30 \mathrm{~mm}$ in diameter.

\section{EYELID}

In the right ventral eyelid of $\mathrm{C} 9$ was a focal purulent sinus tract that extended from the surface for $20 \mathrm{~mm}$ into the eyelid and was $5 \mathrm{~mm}$ wide. There was extensive purulent inflammation of the eyelid and surrounding subcutaneous tissues. This lesion may have been a traumatic injury and probably resulted in the hyperplastic lesions observed in the right parotid and right retropharyngeal lymph nodes (see above) of this animal.

\section{Histopathology}

The microscopical lesions of the organs mentioned above, except for the eyelid, as well as significant lesions detected in other organs are described below. The multinucleated giant cells encountered were always a mixed cell population consisting of both the Langhans' and foreign-body types. All le- sions in all organs were negative for acid-fast bacilli with ZN staining.

\section{KIDNEY}

The focal lesion in the right kidney of $\mathrm{C} 1$ consisted of a central area of caseous necrosis that contained necrotic cellular debris, mostly necrotic neutrophils, and showed early calcification. This was surrounded by moderate numbers of macrophages and epithelioid cells, and numerous lymphocytes and plasma cells. There was a fairly well-developed outer layer consisting of fibrous connective tissue.

\section{LIVER}

The macroscopic multifocal pale white foci in the liver consisted of nodular aggregations of a mixture of moderate to large numbers of lymphocytes, plasma cells and eosinophils in portal tracts, and occasionally in the parenchyma. C25 had a small focal granuloma in a portal tract consisting of a central area of coagulative necrosis surrounded by small numbers of macrophages and epithelioid cells. In one animal $(\mathrm{C} 1)$ there was a small focal empty cyst in the parenchyma that was surrounded by a thin layer of degenerative and necrotic hepatocytes, with haemorrhage and infiltration of moderate numbers of neutrophils and eosinophils. The cyst was probably parasitic in nature and had a thin outer wall, with an inner adherent single row of spindleloid cells projecting into the cyst cavity. All animals, except $\mathrm{C} 9$ and $\mathrm{C} 20$, showed infiltration of scanty to moderate numbers of lymphocytes, plasma cells and eosinophils in the portal tracts, without the formation of distinct nodules. The lesions present in the liver were probably in response to previous parasitic larval migration.

The liver of C4 displayed multifocal areas, consisting of one to multiple open fusiform slits or clefts throughout the parenchyma, and also involving portal tracts. The cleft aggregates were surrounded by low to moderate numbers of macrophages, epithelioid cells and fibroblasts, with occasional multinucleated giant cells and small numbers of lymphocytes, plasma cells and eosinophils. The cause of the clefts could not be established but they are unlikely to have been related to tuberculosis.

\section{LYMPH NODE}

The prescapular lymph nodes and right mandibular lymph node of $\mathrm{C} 1$, and the right parotid and right retropharyngeal lymph nodes of C9 displayed typical reactive hyperplastic changes, without evidence 
of possible tuberculosis. These changes were marked and consisted of numerous cortical secondary reactive follicles with prominent germinal centres, necrosis of individual lymphocytes in follicles with increased tingible-body macrophage activity, a prominent hyperplastic paracortical zone and sinus histiocytosis.

The following lymph nodes showed focal to multifocal microscopic granulomatous lymphadenitis: mesenteric (C1, C2, C9, C10, C11, C12, C13, C14, C16, C17, C18, C20, C21, C22, C23, C24 and C25), ileocaecal (C1, C8, C12, C16, C19, C24 and C25), bronchial (C1 and C7) and inguinal (C20). The lesions were characterized by variable numbers (usually single) of centrally-located nematode larvae, or their necrotic remnants, in the following animals: mesenteric lymph nodes of C1, C2, C9, C11, C12, C17 and C25; ileocaecal lymph nodes of C1, C8, C12, C19 and C24; bronchial lymph nodes of C1 and C7; and the inguinal lymph nodes of C20. The nematode larvae were occasionally surrounded by low to moderate numbers of eosinophils that often displayed degenerative and necrotic changes. Granulomas without central nematode larvae occasionally showed central caseous necrosis. All animals showed infiltration of variable numbers of a mixture of macrophages, epithelioid cells, multinucleated giant cells, lymphocytes, plasma cells and eosinophils around the central parasite or necrotic area.

The bronchial and mediastinal lymph nodes of C22 showed accumulations of moderate to large numbers of macrophages, containing cytoplasmic foreign particulate matter, in the cortex and medulla. The macrophages were often arranged in nests.

\section{TONSILS}

One of the tonsils of $\mathrm{C} 2$ displayed a focal granuloma that consisted of a central area of caseous necrosis surrounded by moderate numbers of macrophages. Moderate numbers of small plant fibres were present in the crypts and it is likely that the granuloma was a foreign-body reaction.

\section{SKELETAL MUSCLE}

C20 displayed multifocal, well-defined and variablysized lakes of calcification in muscle and the surrounding connective tissue that were rimmed and separated form each other by moderetaly-developed fibrous connective tissue. The connective tissue was infiltrated by moderate to large numbers of lymphocytes and plasma cells, and small to moder- ate numbers of macrophages. The lesion resembled calcinosis circumscripta.

\section{UTERUS}

The lesions in the uterus of $\mathrm{C} 1$ were marked and consisted of multifocal haemorrhages and coagulative necrosis of the endometrium. The necro-haemorrhagic exudate contained large numbers of bacterial rods morphologically resembling Clostridium spp. The remainder of the endometrium showed infiltration of large numbers of neutrophils, and there was moderate early granulation tissue formation consisting of angiogenesis, macrophage infiltration and fibroplasia. A few endometrial blood vessels contained fibrin thrombi. The lesions probably represented post-partum involution with bacterial endometritis.

The uterus of $\mathrm{C} 5$ showed marked vascular congestion. The endometrium was infiltrated by numerous macrophages that contained abundant cytoplasmic haemosiderin pigment. There were a few multinucleated giant cells and early granulation tissue formation similar to $\mathrm{C} 1$. Small numbers of lymphocytes and plasma cells were also present. The lesions probably reflected post-partum involution.

\section{LUNG}

The following animals showed moderate, multifocal, parasitic, eosinophilic and granulomatous bronchopneumonia with moderate numbers of adult nematodes visible in brionchioles, as well as moderate numbers of larvae present in alveoli: C1, C2, C6 and C8. The lesions consisted of moderate to marked hyperplasia and hypertrophy of bronchiolar epithelium and smooth muscle. There was occasional mild bronchiolar epithelial squamous metaplasia in bronchioles plugged with adult parasites. A few bronchioles were ruptured, resulting in free-lying adult nematodes in the parenchyma that were surrounded by moderate to large numbers of macrophages and multinucleated giant cells, and moderate numbers of lymphocytes, plasma cells and eosinophils. There was widespread infiltration of small to moderate numbers of lymphocytes, plasma cells and eosinophils in the lamina propria of the bronchiolar epithelium, and often perivascularly. Moderate numbers to numerous globular leukocytes, with moderate to abundant, variably-sized, round, eosinophilic, cytoplasmic globules occurred in the intercellular areas of the bronchiolar epithelium. The reaction to the larvae in the alveoli consisted of infiltration of moderate to large numbers of eosinophils, macrophages, multinucleated giant 
cells, lymphocytes and plasma cells, with mild to moderate epithelialization of pneumocytes and mild fibrosis. Similar lesions were present in C5, C7, C9, $\mathrm{C} 16$ and $\mathrm{C} 17$, with $\mathrm{C} 22$ and $\mathrm{C} 25$ showing very mild changes, but no nematode larvae could be found in the alveoli of any of these seven animals.

The following animals showed mild lesions suggestive for nematode infestation, but no parasites were visible: C3, C4, C10, C11, C12, C13, C14, C15, C18, C19, C20, C21, C23 and C24. The lesions in these animals were generally confined to the bronchioles, and consisted of mild to moderate epithelial and smooth muscle hypertrophy and hyperplasia, with infiltration of small numbers of eosinophils, lymphocytes and plasma cells in the lamina propria of the bronchiolar epithelium, and occasionally perivascularly. Low to moderate numbers of globular leukocytes, with moderate to abundant, variablysized, round, eosinophilic, cytoplasmic globules often occurred in the intercellular areas of the bronchiolar epithelium.

\section{ABDOMINAL CAVITY}

The parasitic nodules found in the abdominal cavity of $\mathrm{C} 1$ had a central cavity that was filled with caseous necrotic material that was markedly calcified. The calcified necrotic centre was surrounded by a thin layer of macrophages, multinucleated giant cells, lymphocytes and plasma cells. There was a well-developed fibrous connective tissue capsule.

\section{GASTRO-INTESTINAL TRACT}

Apart from the nematodes causing lesions in the liver, lymph nodes and lungs, several gastro-intestinal tract organs were also infested with parasites. The following animals had scanty to small numbers of nematode larvae present within gastric glands in the abomasum, usually with a negligible to mild lymphocyte, plasma cell and eosinophil inflammatory reaction: $\mathrm{C} 1, \mathrm{C} 2, \mathrm{C} 5, \mathrm{C} 6, \mathrm{C} 7, \mathrm{C} 10$ and $\mathrm{C} 25$. The ileum of $\mathrm{C} 13$ and the jejunum of C25 each had a focal parasitic granuloma in the submucosa and muscle layer, respectively. Both granulomas consisted of a central nematode larva surrounded by small to moderate numbers of macrophages, epithelioid cells, multinucleated giant cells (only C13), lymphocytes and plasma cells. A single nematode parasite was found in the lumen of the jejunum of C24. The following animals showed scanty to small numbers of coccidia, in various stages of their lifecycle, in the epithelium of the mucosa of the colon, with a minimal inflammatory reaction: $\mathrm{C} 4, \mathrm{C} 7, \mathrm{C} 9$, C15, C16, C17, C18, C20, C21 and C24.

\section{Bacteriology}

Mycobacterial culture was performed on the organ pools mentioned above, as well as on an additional pool for $\mathrm{C} 1$ that consisted of specimens from the kidney and uterus. All pools of all animals were negative for Mycobacterium spp. after 10 weeks' incubation.

\section{Summary of results}

Table 1 is a summary of the macroscopical, microscopical and mycobacterial culture results of all 33 springbok. Mycobacterium tuberculosis was confirmed via culture in only three springbok (A1, B4 and B6), indicating a prevalence of $9 \%$. Two (A1 and B4) of the three culture-positive animals displayed tuberculosis lesions, while B6 did not show any significant macroscopic or microscopic pathology.

Mycobacteria other than tuberculosis (MOTT) were isolated from two animals (B2 and B3). B2 was positive for one nest of acid-fast bacilli in one macrophage of a mesenteric lymph node, but no lesions were present.

Table 2 indicates the presence of macroscopic and microscopic lesions, presence of acid-fast bacilli, and organs that did not show lesions for all organs sampled in both animals with tuberculosis lesions.

B4 had prominent macroscopic tuberculosis lesions in the lungs, pleura and bronchial, mediastinal, sternal and iliac lymph nodes. The right prefemoral and right retropharyngeal lymph nodes showed small macroscopic lesions. Microscopic tuberculosis lesions with acid-fast bacilli were present in all the above organs, as well as in the left prefemoral lymph node. The following organs of B4 did show microscopic but not macroscopic lesions that were typical or highly suggestive for tuberculosis, although no acid-fast bacilli were encountered in them: testis, colon and the left retropharyngeal, mesenteric, ileocaecal, inguinal, left mandubular, right mandibular and left prescapular lymph nodes.

In the other affected springbok (A1) marked macroscopic tuberculosis lesions in the lungs, pleura, liver and bronchial- and mediastinal lymph nodes were present. Because this animal was presented for a routine diagnostic necropsy, only a limited set of organs were sampled for microscopy. The only lymph nodes sampled for microscopy in this animal were the bronchial and mediastinal lymph nodes. Microscopic tuberculosis lesions with acid-fast bacilli were present in all the organs of $A 1$ that showed macro- 
TABLE 1 Summary of results

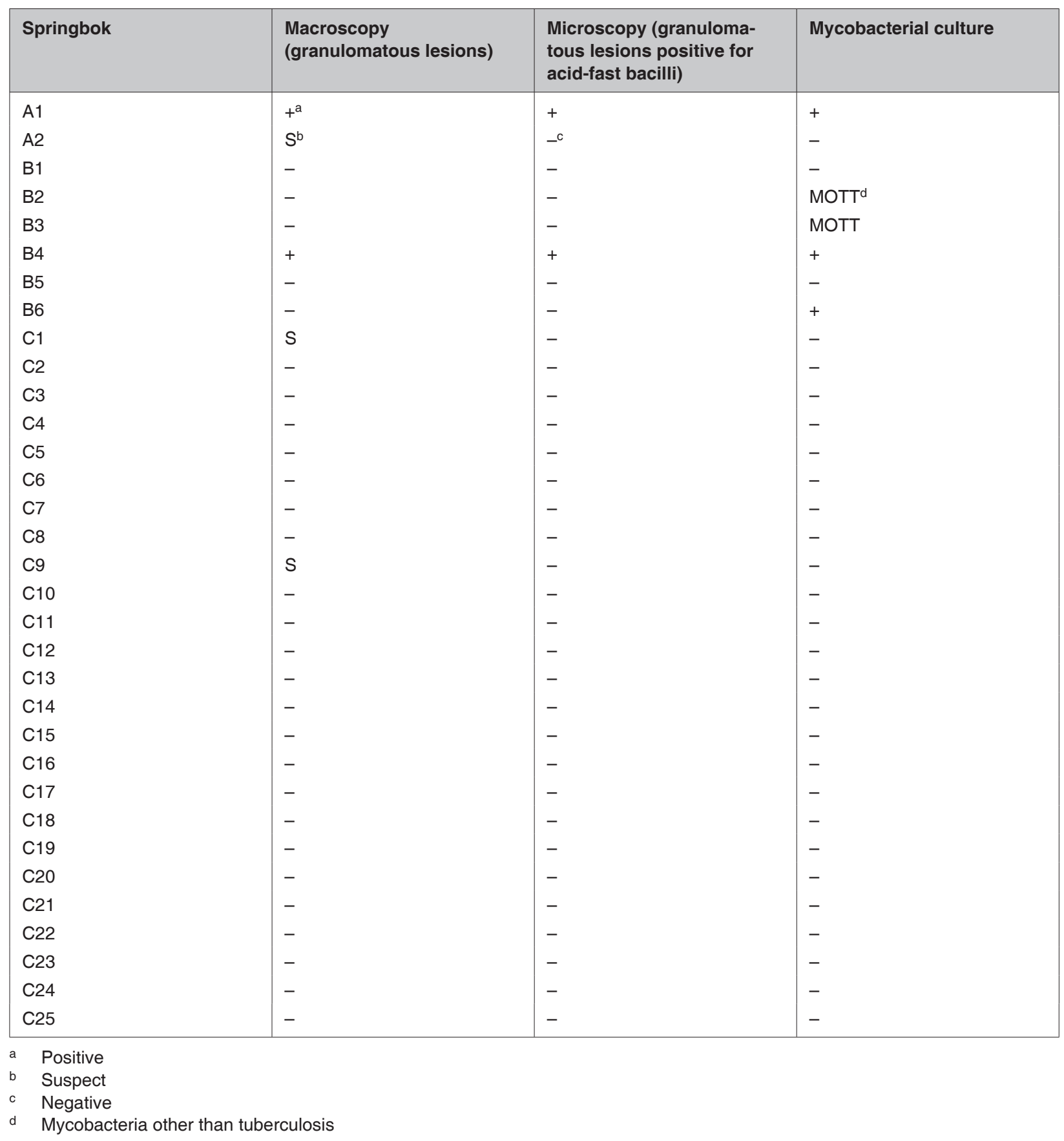

scopic lesions, as well as the following organs: kidney, adrenal gland, abomasum, small intestine, colon and rectum. The heart and oesophagus were also examined, but no macroscopic or microscopic tuberculosis lesions were noted.

Macroscopic lesions encountered ranged from encapsulated (lungs of both animals, pulmonary lymph nodes of A1 and an iliac lymph node of B4) to nonencapsulated (pleura of both and mediastinal lymph node of B4). Macroscopic granulomas with or without obvious caseous necrosis were prominent in the lungs of both, while the iliac lymph node of B4 showed only necrotic foci. The lesions in the pleura of both animals were nodular, plaque-like and proliferative to almost sarcomatous. The liver of $A 1$ showed marked focally disseminate necrosis, which proved to be small necrogranulomas microscopically. The degree of calcification varied from absent (liver of A1) to moderate (lungs and bronchial lymph 
Pathology of tuberculosis caused by Mycobacterium tuberculosis in semi-free-ranging springbok (Antidorcas marsupialis)

TABLE 2 Comparison of organs showing macroscopic and microscopic tuberculosis lesions, acid-fast bacilli and no lesions in the two M. tuberculosis culture-positive springbok (A1 and B4)

\begin{tabular}{|c|c|c|c|c|c|c|c|c|}
\hline \multirow[t]{2}{*}{ Organ } & \multicolumn{2}{|c|}{$\begin{array}{l}\text { Macroscopic } \\
\text { lesions }\end{array}$} & \multicolumn{2}{|c|}{ Microscopic lesions } & \multicolumn{2}{|c|}{ Acid-fast bacilli } & \multicolumn{2}{|c|}{ No lesions } \\
\hline & A1 & B4 & A1 & B4 & A1 & B4 & A1 & B4 \\
\hline Lung & $t^{a}$ & + & + & + & + & + & $-^{\mathrm{b}}$ & - \\
\hline Pleura & + & + & + & + & $N^{c}$ & + & - & - \\
\hline Bronchial In. & + & + & + & + & + & + & - & - \\
\hline Mediastinal In. & + & + & + & + & + & + & - & - \\
\hline Sternal In. & $N S^{d}$ & + & NS & + & NS & + & NS & - \\
\hline Iliac In. & NS & + & NS & + & NS & + & NS & - \\
\hline R-prefemoral In. & NS & + & NS & + & NS & + & NS & - \\
\hline L-prefemoral In. & NS & - & NS & + & NS & + & NS & - \\
\hline R-retropharyngeal In. & NS & + & NS & + & NS & + & NS & - \\
\hline L-retropharyngeal In. & NS & - & NS & + & NS & - & NS & - \\
\hline R-mandibular In. & NS & - & NS & + & NS & - & NS & - \\
\hline L-mandibular In. & NS & - & NS & + & NS & - & NS & - \\
\hline L-prescapular In. & NS & - & NS & + & NS & - & NS & - \\
\hline Mesenteric In. & NS & - & NS & + & NS & - & NS & - \\
\hline lleocaecal In. & NS & - & NS & + & NS & - & NS & - \\
\hline Inguinal In. & NS & - & NS & + & NS & - & NS & - \\
\hline Spleen & - & - & + & - & + & - & - & + \\
\hline Liver & + & - & + & - & + & - & - & + \\
\hline Kidney & - & - & + & - & + & - & - & + \\
\hline Adrenal gland & - & - & + & - & + & - & - & + \\
\hline Testicle & NS & - & NS & + & NS & - & NS & - \\
\hline Abomasum & - & - & + & - & + & - & - & + \\
\hline Small intestine & - & - & + & - & + & - & - & + \\
\hline Colon & - & - & + & + & + & - & - & - \\
\hline Rectum & - & NS & + & NS & + & NS & - & NS \\
\hline Oesophagus & - & - & - & - & - & - & + & + \\
\hline Heart & - & - & - & - & - & - & + & + \\
\hline Brain & NS & - & NS & - & NS & - & NS & + \\
\hline Eyes & NS & - & NS & - & NS & - & NS & + \\
\hline Thymus & NS & - & NS & - & NS & - & NS & + \\
\hline Tongue & NS & - & NS & - & NS & - & NS & + \\
\hline Tonsils & NS & - & NS & - & NS & - & NS & + \\
\hline R-parotid In. & NS & - & NS & - & NS & - & NS & + \\
\hline L-parotid In. & NS & - & NS & - & NS & - & NS & + \\
\hline Hepatic In. & NS & - & NS & - & NS & - & NS & + \\
\hline Splenic In. & NS & - & NS & - & NS & - & NS & + \\
\hline R-prescapular & NS & - & NS & - & NS & - & NS & + \\
\hline R-popliteal & NS & - & NS & - & NS & - & NS & + \\
\hline L-popliteal & NS & - & NS & - & NS & - & NS & + \\
\hline
\end{tabular}

\footnotetext{
a Present

b Absent

c No microscopy done

d Not sampled
}

nodes of both). The size of lesions varied from single pinpoint lesions (right retropharyngeal of B4), to miliary (lungs of both), to multifocal (sternal lymph node of B4 and lungs of both).
The microscopic lesions varied in terms of severity, relative numbers of inflammatory cells, degree and type of necrosis, and abundance of acid-fast bacilli. Lesions were marked in organs such as the lungs, 
pleura and bronchial lymph nodes of both, and liver, spleen and kidney of A1. Mild lesions consisting of individual macrophages or only a few nests of macrophages were present in the adrenal gland, abomasum, small intestine, colon and rectum of $A 1$, and the testes, left and right mandibular lymph nodes, and left prescapular lymph node of B4. Marked granulomatous inflammation, with large numbers macrophages, epithelioid cells and multinucleated giant cells, was present in the lungs and bronchial lymph nodes of both animals, the mediastinal lymph node of $A 1$, and the sternal, iliac, right prefemoral, left prefemoral and right retropharyngeal lymph nodes of B4. The pleura of B4 displayed prominent fibroplasia. Giant cells were of both the Langhans' and foreign-body type, but Langhans' giant cells predominanted in the bronchial and mediastinal lymph nodes of B4. Some granulomas showed central caseous necrosis (lungs and bronchial lymph nodes of both), while necrosis was absent in others, often in the same organ (lungs and bronchial lymph nodes of both, left retropharyngeal and mesenteric lymph nodes of B4). The liver, spleen and kidney of A1 showed prominent multifocal coagulative necrosis of granulomas that were composed of moderate numbers of macrophages, and small numbers epithelioid cells and multinucleated giant cells. The mesenteric and ileocaecal lymph nodes of B4 did not show macroscopic lesions, but prominent microscopic granulomas consisting of large numbers of multinucleated giant cells were present. The giant cells were mostly of the Langhans' type in the case of the mesenteric lymph node. One multinucleated giant cell in the ileocaecal lymph node showed characteristics of both foreign-body and Langhans' giant cells. Multinucleated giant cells in lesions comprised both types, with Langhans' giant cells usually outnumbering the foreign-body type.

Necrogranulomas in the lungs of B4, and bronchial lymph node, spleen and liver of A1 were infiltrated by moderate numbers of neutrophils, but macroscopically visible pus formation was not a feature of the lesions. Small numbers of neutrophils infiltrated the lesions in the lung of $A 1$, and the pleura, left prefemoral and right retropharyngeal lymph nodes of B4.

All the organs of A1 sampled for microscopy, except the oesophagus and heart, showed lesions and the presence of acid-fast bacilli. For B4, the presence of acid-fast bacilli was generally related to the severity of the lesions. They were visible in almost all organs showing macroscopic pathology, while not visible in the organs that only showed microscopic pathology (except for the left prefemoral lymph node). Acidfast bacilli were encountered in B4 in the lungs, pleura and bronchial, mediastinal, sternal, iliac, right prefemoral, left prefemoral and right retropharyngeal lymph nodes. Acid-fast bacilli were numerous (lung, spleen, liver, kidney and the bronchial and mediastinal lymph nodes of A1), moderate in number (adrenal gland of A1 and lung of B4), to small in number (abomasum, small intestine, colon and rectum of $A 1$, and pleura and the following lymph nodes of B4: bronchial, sternal, iliac and right prefemoral). Very rare acid-fast bacilli were visible in the mediastinal, left prefemoral and right retropharyngeal lymph nodes of B4.

The tuberculosis and suspected tuberculosis lesions seen in A1 and B4 are summarized in Table 3. The granulomatous lesions seen in the testes, colon and following lymph nodes: left retropharyngeal, left and right mandibular, left prescapular, mesenteric, ileocaecal and inguinal of B4 are included in the table as tuberculosis lesions, even though no acid-fast bacilli were detected. The multifocal granulomas in the colon of B4 were probably caused by migrating nematode larvae, but sections of a nematode larva were encountered in only one of the four granulomas.

\section{DISCUSSION}

This study represents the first confirmed cases of M. tuberculosis in springbok. Previous reports of tuberculosis in springbok did not conclusively establish the Mycobacterium species involved, and no detailed description of the pathology was given (Robinson 1953; Hofmeyr 1956).

Mycobacterium tuberculosis was cultured from three springbok (A1, B4 and B6), indicating a prevalence of $9 \%(3 / 33)$, but only two (A1 and B4) showed tuberculosis lesions. This emphasizes the importance of mycobacterial culture in diagnostic surveys for tuberculosis. There is no documented information on the prevalence of $M$. tuberculosis in infected semi-free-ranging and free-ranging wildlife. This is not surprising, as HTB is exceptionally rare in wildlife populations not kept in captivity, although it may be an important emerging disease in certain freeranging wildlife species in some regions of the world (Alexander et al. 2002). In captive wildlife, M. tuberculosis was found to be the third most frequently isolated mycobacterium (11\%) among a total of 263 mycobacterial isolates obtained from zoos and wildlife parks in the United States of America in the mid1970s (Thoen et al. 1977). Between 1991 and 2001 


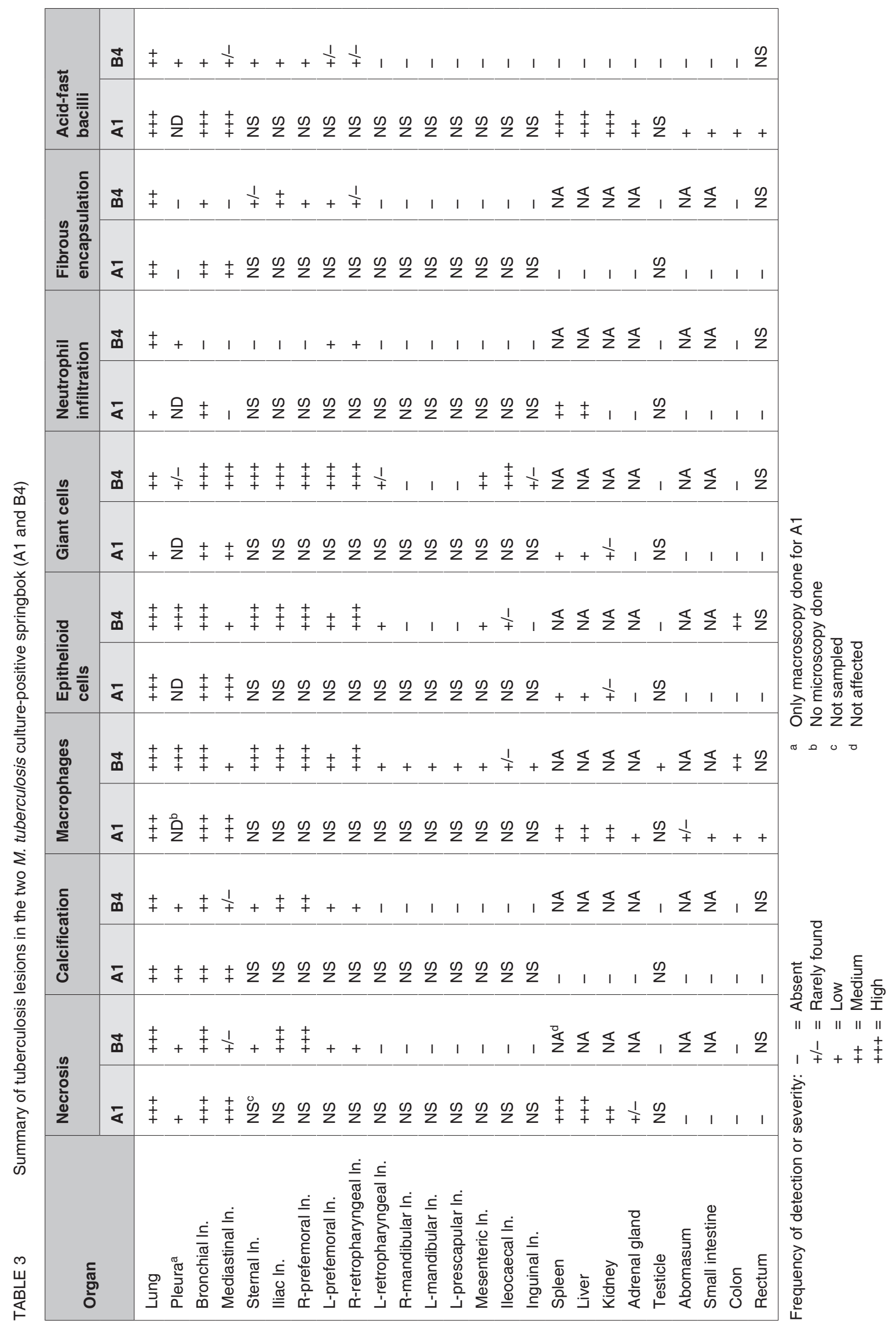


a total of 12 cases of $M$. tuberculosis infection in eight different species were recorded at the National Zoological Gardens of South Africa in Pretoria (Michel et al. 2003).

The generalized nature of the lesions in both affected springbok makes it difficult to establish the route of infection, although the oral route appears most likely. The lung lesions in both animals involved the interstitium and alveolar walls rather than the bronchioles which strongly suggests the oral route of infection. However, the pulmonary lymph nodes in both animals showed marked macroscopic lesions, while the mesenteric and ileocaecal lymph nodes only showed moderate lesions, suggesting infection via inhalation. The behavioral pattern of springbok would have facilitated exposure to human excretions in the environment, supporting the oral route of infection. Investigations into the possible source of infection revealed that two of the groundskeepers were under treatment for confirmed $M$. tuberculosis infection $(\mathrm{H}$. Kettner, personal communication 2000). The springbok were semifree-ranging and never handled, so it is highly unlikely that aerosol transmission occurred from the infected humans to the springbok. The lung lesions in the springbok were not markedly encapsulated and the possibility of aerosol shedding from open lung lesions, and subsequent intraspecific transmission after the initial infection should also be considered.

Cattle infected with $M$. tuberculosis usually do not develop progressive disease and typically only show small granulomas in the pharyngeal, thoracic and mesenteric lymph nodes (Dungworth 1993; O'Reilly \& Daborn 1995; Cousins, Huchzermeyer, Griffin, Brückner, Van Rensburg \& Kriek 2004). Captive and free-ranging wildlife, however, often develop extensive lesions and progressive pulmonary disease after infection with $M$. tuberculosis (Lomme, Thoen, Himes, Vinson \& King 1976; Montali et al. 2001; Alexander et al. 2002). Generalized or miliary tuberculosis occurs when there is haematogenous dissemination of both free and macrophage-associated mycobacteria from the primary site of infection throughout the body. This is most frequently the result of breakdown of a blood vessel by an expanding caseating granuloma or cavitating lesion (Dungworth 1993; López 2001). Susceptible hosts also tend to develop rapidly progressing generalized lesions more readily than resistant animals (De Lisle, Bengis, Schmitt \& O'Brien 2002), indicating that springbok should be regarded as highly susceptible. Lesions were found in numerous organs (Table 3 ), and it is likely that $A 1$ would have shown lesions in many more organs if sampling had been done more extensively.

The lesions observed in the two affected springbok were dissimilar in appearance in the various organs. The lesions varied in appearance in terms of extent and macro- and microscopic appearance, as indicated in Table 3. The variability in lesion appearance is probably a reflection of the progression of the infection as determined by the host's cell-mediated immune response, and ranged from early small granulomatous lesions to chronic encapsulated necrogranulomas and proliferative nodules (Dungworth 1993; Neill, Pollock, Bryson \& Hanna 1994; Cousins et al. 2004). This variability in the appearance of tuberculosis lesions has also been noted for African buffalo infected with $M$. bovis in the Kruger National Park of South Africa (Kriek, De Vos, Bengis, Huchzermeyer, Keet \& Raath 1992; Kriek 1994). This pronounced variation should be considered when assessing the macroscopic lesions for diagnostic purposes in single animals.

The macroscopic and microscopic appearance of the tuberculosis lesions in the springbok mostly conformed to the classical tuberculous granulomatous inflammatory lesions as described for humans, nonhuman primates and various domestic animals and wildlife. More specifically the lesions resembled lesions found in herbivores and omnivores (Francis 1958; Thoen \& Himes 1981; Dungworth 1993). There were indistinct to discrete granulomas with or without central caseous necrosis, surrounded by variable, but usually numerous, macrophages, epithelioid cells, multinucleated giant cells, lymphocytes and plasma cells. Fibrous encapsulation was absent to moderate. Calcification was generally mild to moderate and microscopic neutrophil infiltration was only occasionally observed. The pleural nodular lesions were more proliferative, with prominent fibroplasia. Multinucleated giant cells consisted of both Langhans' and foreign-body types, with Langhans' giant cells occasionally predominating. This is in accordance with Thomson (1984) who states that the distinction between Langhans' and foreign-body giant cells is not valid, as both types are found in the same lesions and there is no relationship between the type and aetiological agent. Acid-fast bacilli were scanty to numerous, with large clumps visible in the necrotic exudate of the pulmonary lymph nodes of one animal. Some organs showed typical or highly suggestive tuberculous granulomatous lesions but acid-fast bacilli could not be detected. This marked variation in numbers of acid-fast bacilli, and even absence, in typical lesions is commonly found in cattle (Cousins et al. 2004). 
Some animals, notably certain wildlife species, show obvious differences regarding the appearance and distribution of lesions when compared to those observed in cattle infected with $M$. bovis (De Lisle et al. 2002). The lesions in the springbok differed from those in cattle mainly in the degree of calcification. The springbok showed minimal to moderate calcification while cattle often show marked calcification of caseous necrogranulomas (Dungworth 1993). Renal lesions in cattle are limited to the cortex (Dungworth 1993). The renal lesions in A1 occurred in the cortex but were confined to the cortico-medullary junction. Acid-fast bacilli were numerous in the renal granulomas but there were also rare acid-fast bacilli in the mesangial cells of renal corpuscles. Abscessation and fistulation of the parotid lymph nodes are common findings in greater kudu infected with $M$. bovis (Bengis \& Keet 1998; Keet, Kriek, Bengis \& Michel 2001), but absent in most other species, including springbok. In contrast to herbivores and omnivores, certain carnivore species such as lions show lesions that are more proliferative in nature without caseation, calcification or multinucleated giant cells, but acid-fast bacilli are often numerous (Keet et al. 1996; Keet, Kriek, Penrith \& Michel 1998; De Lisle et al. 2002). The proliferative nodular lesions in the pleura of the springbok resembled the pleural lesions of cattle (Dungworth 1993), and showed, in contrast to those in lions, caseation, calcification and acid-fast bacilli. Scanty multinucleated giant cells were found in the pleural lesions of the springbok.

There are few detailed reports on the pathology of $M$. tuberculosis in wildlife. Most reports only superficially mention or describe the pathology, and concentrate mainly on the epidemiology, mycobacteriology or zoonotic aspects of the disease (Thoen et al. 1977; Michalak et al. 1998; Oh, Granich, Scott, Sun, Joseph, Stringfield, Thisdell, Staley, WorkmanMalcolm, Borenstein, Lehnkering, Ryan, Soukup, Nitta \& Flood 2002; Michel et al. 2003).

There is only one report that gives some indication of the pathology of probable $M$. tuberculosis infection in springbok. In this report, two springbok from the Pretoria Zoological Gardens showed extensive tuberculosis lesions of the lungs, with numerous acid-fast bacilli in smears from the lung lesions. One of the springbok displayed pus in the lesions that was of a soft creamy consistency (Robinson 1953). The two springbok with tuberculosis lesions in the present study also showed extensive lung lesions with moderate to large numbers of acid-fast bacilli, but no macroscopically visible pus.
Two East African Oryxes (Oryx gazella beisa) from the same pen at the Jackson Zoological Park in Missouri, USA, had tuberculosis as a result of $M$. tuberculosis infection. One animal died from tuberculosis while the other was euthanased as a result of a positive IDT test. Both showed generalized disease with extensive necrogranulomatous lesions in the lungs, liver, mediastinal and mesenteric lymph nodes. One animal also had necrogranulomas in the uterus. Acid-fast bacilli were visible in the affected organs (Lomme et al. 1976). The lesions were generally similar in the springbok, but neither A1 or B4 had macroscopically visible lesions in the mesenteric lymph nodes. Springbok A1 was a ewe but the uterus was not sampled for microscopic analysis, and therefore the presence of lesions could not be confirmed, although there were no macroscopic lesions.

Mycobacterium tuberculosis infection in captive Asian elephants (Elephas maximus) results in necrogranulomas primarily in the lungs and thoracic lymph nodes. In animals suffering from extensive involvement of both lungs, severe calcified necrogranulomas and cavitating lesions with pulmonary abscesses develop that often cause the death of the animal. Typical microscopic findings include granulomas with giant cells in the lymph nodes and lungs initially, that progress to extensive necro- and pyogranulomatous pneumonia in advanced cases. Acid-fast bacilli are sparsely distributed but more easily found in central areas of caseation in the lungs, rather than in the lymph nodes where they are usually rare (Montali et al. 2001). Springbok A1 was markedly weakened and recumbent when it was euthanased for necropsy. This animal would have probably died naturally from tuberculosis, indicating that tuberculosis can be fatal, similar to the East African Oryx and Asian elephant. Springbok B4, however, had tuberculosis as an incidental finding. Although the springbok showed marked lesions in the lungs, there was never cavitation or abscessation, and only moderate calcification. The numbers of acid-fast bacilli in the springbok were low to numerous, with large numbers visible in the necrotic exudate of the lungs, and bronchial and mediastinal lymph nodes of $\mathrm{A} 1$.

Humans and non-human primates infected with $M$. tuberculosis typically show pulmonary disease with involvement of pulmonary lymph nodes, and occasionally systemic dissemination. Macroscopic granulomas are characterized by caseation and cavitation. Microscopically the lesions display classical tuberculous granulomatous inflammation with calci- 
fication, fibrous encapsulation and variable numbers of acid-fast bacilli (Thoen \& Himes 1981; Kumar, Cotran \& Robbins 1997; Montali et al. 2001). The springbok in the current study had similar lesions but cavitation was not a macroscopic feature.

The main differential diagnosis for the tuberculosis lesions in the springbok was granulomatous inflammation caused by migrating nematode larvae. Adult $B$. magna lungworms in the airways of the lungs did not cause granulomatous inflammation, except where bronchioles had ruptured. Granulomas occurred in the lungs, various lymph nodes, but mostly the mesenteric lymph node, tonsil, liver, kidney and gastro-intestinal tract. Inspissated and calcified parasitic larval nodules occurred in the abdominal cavity attached to the liver and abomasum of two animals. The lesions were differentiated from tuberculous granulomas by the presence of larvae in cross-section of most granulomas, the absence of acid-fast bacilli, and infiltration of eosinophils. Many animals had multifocal nodular aggregations of lymphocytes and plasma cells with variable numbers of eosinophils in the liver, particulary the portal tracts. These aggregations probably represent lymphoid follicles in response to parasitic migration and were all negative for acid-fast bacilli.

The focal granuloma in the kidney of $\mathrm{C} 1$ resembled a typical tuberculous granuloma both macroscopically and microscopically, but no acid-fast bacilli were visible. The uterus of $\mathrm{C} 1$ and $\mathrm{C} 5$ showed necro-haemorrhagic bacterial endometritis and granulomatous endometritis, respectively. These lesions probably reflect post-partum involution, with bacterial infection in the case of $\mathrm{C} 1$. The lesions did not show acid-fast bacilli, and mycobacterial culture of pooled kidney and uterus specimens from $\mathrm{C} 1$ was negative. The gastrocnemius muscle of $\mathrm{C} 20$ displayed bilaterally symmetrical areas of calcification macroscopically, which was determined to be calcinosis circumscripta microscopically. The liver of C20 showed multifocal granulomatous inflammation that surrounded groups of open fusiform clefts. The cause of the clefts could not be established but they probably contained an immunogenic substance which elicited a foreign-body reaction. Acid-fast bacilli could not be found in the lesions, and the animal was culture-negative for mycobacteria.

Mycobacterial culture is regarded as the gold standard for diagnosing tuberculosis (De Lisle et al. 2002). Mycobacterium tuberculosis was cultured from three springbok (A1, B4 and B6) in this study, but only two had displayed lesions of tuberculosis.
The historical literature is often ambiguous as to the identity of mycobacteria isolated from animals with tuberculosis. The paper by Robinson (1953) on tuberculosis of springbok indicates that pure cultures of $M$. tuberculosis were obtained from one animal. However, subsequent cultures from guinea pigs that were inoculated with affected lung material were considered to be of the bovine type. An incontact springbok that died shortly afterwards yielded a pure culture $M$. tuberculosis, but inoculation of guinea pigs was never attempted. The identity of the causative Mycobacterium species in both these cases should be regarded as equivocal, although $M$. bovis may have been involved. The case of tuberculosis mentioned by Hofmeyr (1956) gives no additional information regarding the causative $\mathrm{My}$ cobacterium species. Springbok B6 did not show any macroscopical or microscopical tuberculosis lesions, and the isolation was made from the organ lymph node pool. This pool comprised the bronchial, mediastinal, hepatic, splenic, ileocaecal and mesenteric lymph nodes. This animal could therefore have been infected via either the oral or inhalation route, with bacterial spread to lymph nodes draining either the lungs or gastro-intestinal tract. Springbok B6 may have been sampled during the early infection phase before there was enough time for detectable lesions to develop. Another possible reason for the absence of lesions is localized containment of the infection as a result of an effective immune response.

The isolation of MOTT from B2 and B3 indicates that these animals were exposed and infected by environmental mycobacteria, without the development of tuberculosis lesions. Springbok B2 showed a single cluster of acid-fast bacilli in the cytoplasm of a macrophage in a mesenteric lymph node, without an inflammatory reaction. These acid-fast bacilli were short, straight and thick-set rods, in contrast to the $M$. tuberculosis bacilli in the infected springbok which were all medium to fairly long, slender and often curved. Although the microscopic morphology of acid-fast bacilli cannot be used to identify the causative organism, the morphological difference between the MOTT and $M$. tuberculosis was striking. The morphology of $M$. bovis appears similar to M. tuberculosis (Cousins et al. 2004). This difference may therefore be a useful microscopical indicator of the Mycobacterium species involved, although mycobacterial culture will always be needed to confirm the identity.

Although the source of infection could not be established conclusively, it is likely to be one or both of 
the M. tuberculosis positive groundskeepers. Unfortunately, both groundskeepers terminated their employment several months before the index case, and it was not possible to obtain $M$. tuberculosis isolates from them for genomic typing to confirm transmission. Although the initial infection of the springbok at iThemba LABS is likely to be from humans (zooanthroponosis), subsequent intraspecific transmission cannot be ruled out. Tuberculosis was not recorded in any of the other wildlife species on the property during the study period, and only time will tell if they are also infected. The wildlife at iThemba LABS are kept in a semi-free-ranging state on the grounds, which is securely fenced, and it is unlikely that they will act as a source of infection for humans. The site is also closed to the general public. iThemba LABS is situated in the Cape Town metropole, which has one of the highest reported incidence rates of tuberculosis in humans in the world (Anon. 2001; Anon. 2004). With this high incidence rate in humans, the zooanthroponotic risk of tuberculosis is far greater than the zoonotic potential of tuberculosis in this area.

\section{ACKNOWLEDGEMENTS}

We express our gratitude to Drs Gideon Brückner and James Kitching of the Directorate Veterinary Services, Western Cape Department of Agriculture for funding of the mycobacterial cultures, and allowing us the use of their necropsy facilities; to Messrs Paul Slingers and Chrisjan Jantjes for assisting with the necropsies; to Dr Horst Kettner of the iThemba LABS Staff Environmental Club for organizing and assisting with the culling of the springbok; to Dr Anita Michel and her staff at the Tuberculosis Laboratory of the ARC Onderstepoort Veterinary Institute for conducting the mycobacterial examinations; to Messrs Errol van Kerwel and André Meyer, and Ms Gwen du Plessis at PathCare for the processing, sectioning and staining of all the histopathological sections, and to Prof. Joop Boomker of the Department of Veterinary Tropical Diseases, Faculty of Veterinary Science, University of Pretoria for identification of the nematodes.

\section{REFERENCES}

ALEXANDER, K.A., PLEYDELL, E., WILLIAMS, M.C., LANE, E.P., NYANGE, J.F.C. \& MICHEL, A.L. 2002. Mycobacterium tuberculosis: an emerging disease of free-ranging wildlife. Emerging Infectious Diseases, 8:598-601.

ANON. 1983. Laboratory manual. Tuberculosis Laboratory, Section of Bacteriology. Onderstepoort Veterinary Institute, Pretoria, South Africa.
ANON. 2001. South African National Tuberculosis Association. Latest tuberculosis statistics. http://www.santa.org.za/main5. html.

ANON. 2004. Cape Town TB Control. A Partnership between the Provincial Administration of the Western Cape Metropole Region and the City of Cape Town. Progress Report 19972003. http://www.hst.org.za.

BENGIS, R.G. \& KEET, D.F. 1998. Bovine tuberculosis in freeranging kudu (Tragelaphus strepsiceros) in the Greater Kruger National Park complex. Proceedings of the ARCOnderstepoort OIE International Congress with WHOCosponshorship on Anthrax, Brucellosis, CBPP, Clostridial and Mycobacterial diseases, 9-15 August 1998. Pretoria: Sigma Press: 418-421.

BENGIS, R.G., KRIEK, N.P.J., KEET, D.F., RAATH, J.P., DE VOS, V. \& HUCHZERMEYER, H.F.A.K. 1996. An outbreak of bovine tuberculosis in a free-living African buffalo (Syncerus caffer - Sparrman) population in the Kruger National Park: a preliminary report. Onderstepoort Journal of Veterinary Research, 63:15-18.

COSIVI, O., GRANGE, J.M., DABORN, C.J., RAVIGLIONE, M.C., FUJIKURA, T., COUSINS, D., ROBINSON, R.A., HUCHZERMEYER, H.F.A.K., DE KANTOR, I. \& MESLIN, F.-X. 1998. Zoonotic tuberculosis due to Mycobacterium bovis in developing countries. Emerging Infectious Diseases, 4:1-14.

COUSINS, D.V., HUCHZERMEYER, H.F.K.A., GRIFFIN, J.F.T., BRÜCKNER, G.K., VAN RENSBURG, I.B.J. \& KRIEK, N.P.J. 2004. Tuberculosis, in Infectious diseases of livestock with special reference to Southern Africa, $2^{\text {nd }}$ ed., edited by J.A.W. Coetzer \& R.C. Tustin. Cape Town: Oxford University Press.

DE LISLE, G.W., BENGIS, R.G., SCHMITT, S.M. \& O'BRIEN, D.J. 2002. Tuberculosis in free-ranging wildlife: detection, diagnosis and management. OIE Scientific and Technical Review, 21:317-334.

DE LISLE, G.W., MACKINTOSH, C.G. \& BENGIS, R.G. 2001. Mycobacterium bovis in free-living and captive wildlife, including farmed deer in: Mycobacterial infections in domestic and wild animals, edited by E.J.B. Manning \& M.T. Collins. OIE Scientific and Technical Review, 20:86-111.

DUNGWORTH, D.L. 1993. The respiratory system, in Pathology of domestic animals, $4^{\text {th }}$ ed., Vol. 2, edited by K.V.F. Jubb, P.C. Kennedy \& N. Palmer. San Diego: Academic Press.

FORSHAW, D. \& PHELPS, G.R. 1991. Tuberculosis in a captive colony of pinnipeds. Journal of Wildlife Diseases, 27:288295.

FOURIE, P.B. 1983. Tuberculosis in captive wild mammals: the situation in South Africa. South African Journal of Science, 79:345-346.

FRANCIS, J. 1958. Tuberculosis in animals and man. A study of comparative pathology. London: Cassell and Company.

FREDRICKSON, L.E., BARTON, C.E., RAGAN, J.R. \& ROBERTS, J.W. 1971. An epizootic of tuberculosis in a municipal zoo: a public health problem. Journal of the American Veterinary Medical Association, 159:1474-1476.

HOFMEYR, C.F.B. 1956. Two hundred and eighty-four autopsies at the National Zoological Gardens, Pretoria. Journal of the South African Veterinary Medical Association, 27:263282.

KEET, D.F., KRIEK, N.P.J., BENGIS, R.G. \& MICHEL, A.L. 2001. Tuberculosis in kudus (Tragelaphus strepsiceros) in the Kruger National Park. Onderstepoort Journal of Veterinary Research, 68:225-230. 
KEET, D.F., KRIEK, N.P.J., PENRITH, M.-L. \& MICHEL, A. 1998. Tuberculosis in free-ranging lions in the Kruger National Park. Proceedings of the ARC-Onderstepoort OIE International Congress with WHO-Cosponshorship on Anthrax, Brucellosis, CBPP, Clostridial and Mycobacterial diseases. 9-15 August 1998. Pretoria: Sigma Press: 444-453.

KEET, D.F., KRIEK, N.P.J., PENRITH, M.-L., MICHEL, A. \& HUCHZERMEYER, H. 1996. Tuberculosis in buffaloes (Syncerus caffer) in the Kruger National Park: spread of the disease to other species. Onderstepoort Journal of Veterinary Research, 63:239-244.

KRIEK, N.P.J. 1994. Macroscopic assessment of tuberculous lesions in African buffalo (Syncerus caffer). Proceedings of the Tuberculosis in Animals Symposium, 17-18 March 1994. Onderstepoort Veterinary Institue, Pretoria, South Africa.

KRIEK, N.P.J., DE VOS, V., BENGIS, R., HUCHZERMEYER, R., KEET, D. \& RAATH, J. 1992. Pathology of bovine tuberculosis in buffalo in the Kruger National Park. Poster presentation at the Third International Wildlife Ranching Symposium, 27-30 October 1992. CSIR, Pretoria, South Africa.

KUMAR, V., COTRAN, R.S., ROBBINS, S. L. 1997. Lungs and the upper respiratory tract, in Basic Pathology, $6^{\text {th }}$ ed., edited by V. Kumar, R.S. Cotran \& S. L. Robbins. Philadelphia: W.B. Saunders Company.

LOMME, J.R., THOEN, C.O., HIMES, E.M., VINSON, J.W. \& KING, R.E. 1976. Mycobacterium tuberculosis infection in two east African Oryxes. Journal of the American Veterinary Medical Association, 169:912-914.

LÓPEZ, A. 2001. Respiratory system, thoracic cavity, and pleura, in Thomson's special veterinary pathology, $3^{\text {rd }}$ ed., edited by M.D. McGavin, W.W. Carlton \& J.F. Zachary. St. Louis: Mosby, Inc.

MICHALAK, K., AUSTIN, C., DIESEL, S., BACON, J.M., ZIMMERMAN, P. \& MASLOW, J.N. 1998. Mycobacterium tuberculosis infection as a zoonotic disease: transmission between humans and elephants. Emerging Infectious Diseases, 4:283-287.

MICHEL, A.L. \& HUCHZERMEYER, H.F.A.K. 1998. The zoonotic importance of Mycobacterium tuberculosis: transmission from human to monkey. Journal of the South African Veterinary Association, 69:64-65.
MICHEL, A.L., VENTER, L., ESPIE, I.W. \& COETZEE, M.L. 2003. Mycobacterium tuberculosis infections in eight species at the National Zoological Gardens of South Africa, 19912001. Journal of Zoo and Wildlife Medicine, 34:364-370.

MONTALI, R.J., MIKOTA, S.K. \& CHENG, L.I. 2001. Mycobacterium tuberculosis in zoo and wildlife species, in Mycobacterial infections in domestic and wild animals, edited by E.J.B. Manning \& M.T. Collins. OIE Scientific and Technical Review, 20:291-303.

NEILL, S.D., POLLOCK, J.M., BRYSON, D.B. \& HANNA, J. 1994. Pathogenesis of Mycobacterium bovis infection in cattle. Veterinary Microbiology, 40:41-52.

OH, P., GRANICH, R., SCOTT, J., SUN, B., JOSEPH, M., STRINGFIELD, C., THISDELL, S., STALEY, J., WORKMANMALCOLM, D., BERENSTEIN, L., LEHNKERING, E., RYAN, P., SOUKUP, J., NITTA, A. \& FLOOD, J. 2002. Human exposure following Mycobacterium tuberculosis infection of multiple animal species in a metropolitan zoo. Emerging Infectious Diseases, 8:1290-1293.

O'REILLY, L.M. \& DABORN, C.J. 1995. The epidemiology of Mycobacterium bovis infections in animals and man: a review. Tubercle and Lung Disease, 76 Supplement 1:1-46.

ROBINSON, E.M. 1953. A few cases of tuberculosis. Journal of the South African Veterinary Medical Association, 24:97-99.

STETTER, M.D., MIKOTA, S.K., GUTTER, A. F., MONTEROSSO, E.R., DALOVISIO, J.R., DEGRAW, C. \& FARLEY, T. 1995. Epizootic of Mycobacterium bovis in a zoological park. Journal of the American Veterinary Medical Association, 207: 1618-1621.

THOEN, C.O. 1988. Tuberculosis. Journal of the American Veterinary Medical Association, 193:1045-1048.

THOEN, C.O. \& HIMES, E.M. 1981. Tuberculosis, in Infectious diseases of wild animals, edited by J.W. Davis, L.H. Karsted \& D.O. Trainer. Ames: lowa State University Press.

THOEN, C.O., RICHARDS, W.D. \& JARNAGIN, J.L. 1977. Mycobacteria isolated from exotic animals. Journal of the American Veterinary Medical Association, 170:987-990.

THOMSON, R.G. 1984. General veterinary pathology. Philadelphia: W.B. Saunders Company. 